\title{
FIRE SPOT IDENTIFICATION BASED ON HOTSPOT SEQUENTIAL PATTERN AND BURNED AREA CLASSIFICATION
}

\author{
IMAS SUKAESIH SITANGGANG ${ }^{*}$, NALAR ISTIQOMAH¹ AND LAILAN SYAUFINA² \\ ${ }^{1}$ Department of Computer Science, Faculty of Natural Science and Mathematics, Institut Pertanian Bogor, Bogor 16680, Indonesia \\ ${ }^{2}$ Department of Silviculture, Faculty of Forestry, Institut Pertanian Bogor, Bogor 16680, Indonesia
}

Received 14 July 2016 / Accepted 17 May 2018

\begin{abstract}
Indonesia has the world's largest tropical peatlands of about 14.9 million hectares that have important life support roles. However, fire frequently occurs in peatlands. According to experts and field forest fire fighters, fire hotspots that appear in a sequence of two to three days at the same location has a high potential of becoming a forest fire. This study aimed to determine the sequential patterns of hotspot occurrences, classify satellite image data and identify the fire spots. Fire spot identification was done using hotspot sequence patterns that were overlaid with burned area classification results. Sequential pattern mining using the Prefix Span algorithm was applied to identify sequences of hotspot occurrence. Maximum Likelihood method was applied to classify Landsat 7 satellite images toward identifying burned areas in Pulang Pisau and Palangkaraya in Central Kalimantan and Pontianak in West Kalimantan. Sequence patterns were overlaid with image classification results. The study results show that in Pulang Pisau, $26.19 \%$ of sequence patterns are located in burned areas and $72.62 \%$ sequence patterns were found in the buffer of burned area within a radius of one kilometer. As for Palangkaraya, there were $62.50 \%$ sequence patterns located in burned areas and $87.50 \%$ sequence patterns in the buffer of burned area with the radius of one kilometer. In total, there were $72.62 \%$ and $87.50 \%$ fire hotspots recorded in Pisau and Palangkaraya, respectively which are strong indicators of peatland fires.
\end{abstract}

Keywords: fire spot identification, hotspot, maximum likelihood, Prefix Span, sequential pattern mining

\section{INTRODUCTION}

Indonesia has the world's largest peatlands with 17 to 21 million hectares of peatland forest (Syaufina 2008). Peatlands have important ecological roles such as the storage of water during rainy season that will be released as water supply in the dry season. The capacity of peatlands to absorb water in rainy season can also prevent floods. Peatlands also serve as habitat for many animals, including fish. Indonesia's peatlands are spread over several islands including Sumatera, Kalimantan and Papua.

Unfortunately, many fires happen nowadays in peatlands. This causes numerous environmental impacts, including loss of

${ }^{*}$ Corresponding author: imas.sitanggang@ipb.ac.id biomass and biodiversity, subsidence, loss of ecosystem function including carbon sequestration, and the emergence of smog causing health and transportation problems (Syaufina 2008). Peatland fires are ground or subsurface fires, spreading under the surface with no flaming but smoldering (Syaufina 2008). Compared to other fire types, ground fires may kill trees and shrubs growing on the surface as they burn through and damage the roots. Such fires make firefighting difficult, with the fallen and dead trees that are still standing upright also complicating firefighting. In the smoldering peat, fires can last longer and produce dense smoke. Thus, peatland fires are more dangerous than non-peat fires.

Several studies on peatland have been conducted. Sitanggang et al. (2014) applied a spatial decision tree algorithm on spatial data of 
forest fires resulting in a pruned spatial decision tree with 122 leaves with accuracy of $71.66 \%$. This study also found that the spatial trees produced a higher accuracy than the non-spatial trees that were created using the ID3 and C4.5 algorithm. The ID3 had an accuracy of $49.02 \%$ and C4.5 produced $65.24 \%$ accuracy. Sitanggang (2013) also conducted a study to discover the possible influence factors on the occurrence of fire events using Apriori algorithm in Rokan Hilir Riau Province, Indonesia. The Apriori algorithm was applied on a forest fire dataset which contained data on physical environment, socio-economic, weather and peatlands. The results showed that there are strong relationships between hotspot occurrence and influential factors for the support about $12.42 \%$, the confidence of 1 , and the lift of 2.26 . Moreover, Kirana et al. (2015) used Kulldorff's Scan Statistics (KSS) method with Poisson model to recognize the distribution pattern of hotspot clusters in Sumatra peatland areas in 2014. The results showed that the method is reliable to detect the clusters of hotspots which have a $95 \%$ accuracy.

The occurrence of fire hotspots is used as forest fire indicator. Hotspot data have been widely collected by various institutions. Meanwhile, experts and practitioners stated that the hotspots that appear two or three days in sequence at the same location have a high potential of becoming a forest fire. Therefore, sequential pattern mining can be applied to obtain hotspot sequence patterns for fire identification.

Research on sequential pattern mining has been carried out by Nurulhaq and Sitanggang (2015). This study conducted sequential pattern mining of data hotspots in Riau Province in 2000 until 2014 using the PrefixSpan algorithm. The occurrences of a sequential pattern of hotspots were generated each year with several values of the minimum support. The sequential pattern of hotspot in 2013 and 2014 were analyzed because the number of hotspot occurrences was greater than the previous years. This study produced patterns that have length up to 4 hotspot occurrences in 2013 and 3 hotspot occurrences in 2014.

However, hotspot occurrences do not necessarily indicate the occurrence of forest fires. So land managers typically have to check hotspots in the field to find out if the hotspot is a forest fire or not. This requires much time and cost, especially for areas that are difficult to reach. Therefore, there is a need for an easy and efficient validation method of sequence patterns of hotspot occurrence.

To observe the extent and impact of the peatland fires, technologies can provide information that cover large areas as needed. One of them is remote sensing, usually done from satellites, but also from aircraft and increasingly from drones. Location of fires, intensity of fires and burned area can be determined easily and effectively from satellite (Justice et al. 1993). One method that can be used is satellite imagery classification. Several studies have been conducted in this field, one of them was by Mitri and Gitas (2002) using object-oriented classification model. In this study, satellite imagery from Mediterania Spanyol was classified to identify burned area. This identified a total burned area of 6900 ha, with a $90 \%$ accuracy.

Khaira et al. (2016) also performed satellite image classification using SVM. In this study, Landsat 5 and 7 images were classified to determine the land cover changes; the accuracy of classification was $98.2 \%$. Then, Thariqa et al. (2016) conducted a comparison of decision tree algorithms to classify satellite imagery. This study revealed that the best algorithms for image classification of forest fires are the C5.0 with an accuracy of $99.79 \%$.

Moreover, Sitanggang et al. (2015) processed Landsat TM image to determine the radius of a hotspot such that random points were generated outside a hotspot buffer as false alarm data. Clustering and majority filtering were performed to extract burn scars in Rokan Hilir, Riau Province, Indonesia. The radius of a hotspot was found to be $0.907 \mathrm{~km}$. Beside the ID3 algorithm, C4.5 and extended spatial ID3 have been applied. This produced decision trees for modeling hotspot occurrence which have the accuracy of $49.02 \%$ for the ID3 decision tree, $65.24 \%$ for the C4.5 decision tree, and $71.66 \%$ for the extended spatial ID3 decision tree.

In addition, there are other image classification algorithms that can be used ( $\mathrm{Lu}$ 2007). One of them is the per-pixel classification approach that can be done with maximum 
likelihood method. This method has advantages such as its robustness and wide availability in almost all image processing software (Lu 2007). Maximum likelihood estimates less parameters, thus, can classify images very quickly (Canty 2010). The results of the classification of satellite imagery can be used to validate the hotspots sequence pattern. By overlaying the results of image classification with the hotspots sequences pattern, we can identify whether sequence patterns are located in burned areas or not. Hotspots sequence pattern in burned areas are called the true fire occurrences.

Based on explanation above, the question arises on how to identify fire spots on the hotspots sequences pattern and satellite image burned area classification. To answer this question, a study was conducted to do sequential pattern mining of hotspot data using the Prefix Span algorithm. The results of hotspot sequences pattern were then evaluated using satellite image data that were classified by the maximum likelihood method. The purpose of this study is to obtain sequential patterns of hotspots occurrence using the Prefix Span algorithm, to apply the maximum likelihood method to classify satellite image data of burned area and, ultimately to identify the fire spots. Fire spot identification was done using hotspots sequences patterns that overlaid with burned area classification results.

\section{MATERIALS AND METHODS}

\section{Study Area and Datasets}

This study focused on the peatlands in West Kalimantan and Central Kalimantan, Indonesia were many peatland fires occur. This study used satellite imagery Landsat 7, peatland map data, and hotspots for 2014 and 2015. Hotspot data were collected from the Fire Information for Resource Management System Moderate Resolution Imaging Spectrometer National Aeronautics and Space Administration (FIRMS MODIS

NASA, https://earthdata.nasa.gov/earth-observationdata/near-real-time/firms). The satellite imagery used for the classification process is Landsat 7 in Pulang Pisau and Palangkaraya, Central Kalimantan province. Landsat 7 images were taken from United States Geological Survey (USGS). Image acquisition date was adjusted to the date of sequences of hotspot and availability of image at the USGS, which was dated October 14, 2015. Peatland map in 2002 was used to select the peat land cover on Landsat satellite imagery. Maps of peatland areas were obtained from Wetlands International.

\section{Research Methods}

This study consisted of three major parts as depicted in Fig. 1, namely: 1) determining sequence patterns of hotspots in 2014 and 2015 using Prefix Span algorithm, 2) classifying satellite image of burn area, and 3) identifying fire spots.

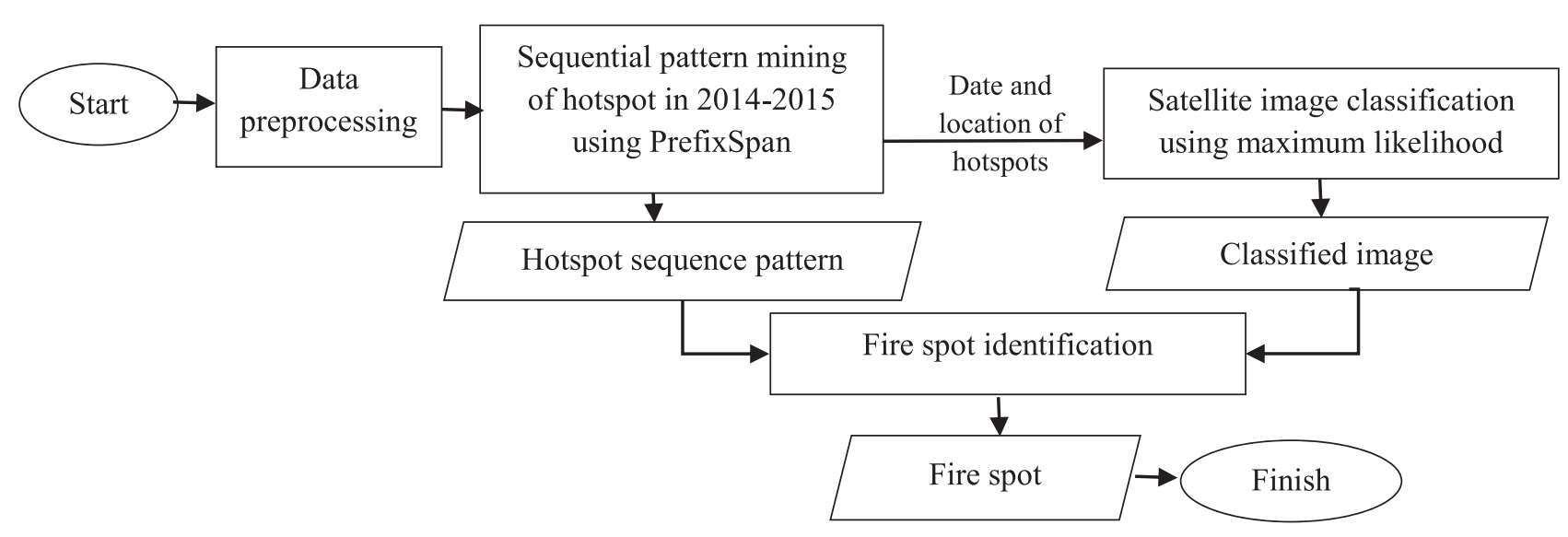

Figure 1 Research steps 


\section{Data Preprocessing}

Data preprocessing consists of data selection, data cleaning, data transformation and generation of data sequential using the $R$ software. In data selection, attributes that will be used in this study were selected. Data cleaning was done by removing the attributes or data that have missing value or noise. In data transformation, the attribute types were transformed. Sequential data were generated by sorting the data by longitude, latitude and date attribute.

Data preprocessing was also performed on satellite image Landsat 7 . Filling the gap on the image, band combination, and subsetting image were done in pre-processing stage. Filling the gap was performed to fill part of image that have no value. Filling the gap was done using gap mask to determine the location of the pixel to be filled. This task was done using Quantum GIS. Moreover, band combination was performed to get the RGB color from the image. Color Red is represented by band 7 , Green is represented by band 4 and Blue is represented by band 2. Furthermore, satellite images were selected to determine area of interest which is peatland.

\section{Sequential Pattern Mining on Hotspot Data}

Sequential data generated from preprocessing stage were used to determine sequential pattern using the PrefixSpan algorithm. PrefixSpan applies a 'divide and conquer' approach that recursively projects the database into a set of smaller data base based on repetitive pattern at the time. Then the projection is used to obtain the patterns. PrefixSpan projects only prefix of the pattern, so the size of the projected database will continue to shrink and redundancy tests on every possible position of potential candidate will be reduced (Pei et al. 2004).

\section{Satellite Image Classification using Maximum Likelihood}

Stages of image classification are image preprocessing, classification using maximum likelihood and filtering classified image. The images as the result of data preprocessing then were classified using the maximum likelihood method. Classification was done utilizing the
ILWIS software. Before performing classification, data sampling is necessary for each image. Samples contain examples of burned and not burned pixels. In this study, samples were taken from the pixel image with band combination of 7, 4 and 2. Red pixel represents burned area, while other pixels represent not burned area. Furthermore, the classification results were filtered. Classification results have salt-and-pepper noises. Noise was removed using the smoothing filter. This study used a majority filter for smoothing image as the results of classification.

\section{Fire spot identification}

According to the results of satellite image classification, pixels which indicate burned and not burned area were identified. Meanwhile, from the results of sequential pattern mining using PrefixSpan, sequences pattern of hotspot occurrences in Kalimantan were extracted from the hotspot dataset. Furthermore, the hotspot sequence patterns were compared with the classified image to identify sequences patterns that are located in burned areas. Hotspot sequence pattern that occurred in burned area are considered as fire spots.

\section{RESULTS AND DISCUSSION}

\section{Data Preprocessing}

In preprocessing stage, data selection, data transformation and data sequential generation were performed. Data selection was done by selecting attributes that will be used in this study. The selected attributes of a hotspot are longitude, latitude and date of acquisition of hotspot. Furthermore, hotspots were selected in the study area namely peatlands in Kalimantan.

In data transformation, the type of attribute acquisition date was converted to integer denoted as date code. In this study, the date codes were from 1 until 730, code 1 representing 1 January 2014 and so on until date code 730 representing 31 December 2015. Data transformation also required the decimal digits of longitude and latitude to be rounded into 2 significant digits. Rounding was performed to obtain more than one hotspot occurrences in a radius of $1 \mathrm{~km}$. 
The last data preprocessing stage is sequential data generation. One sequence is a series of events in one location. Table 1 is an example of sequence of hotspots. According to Table 1, it can be seen that in a location with longitude of 109.48 and latitude of -0.53 , there were hotspot occurrences on day 622 (14 September 2015) and day 629 (21 September 2015). This sequence means that hotspot occurrence at that location has a span of eight days.

Satellite images used in this step were collected from USGS website which can be accessed on http://earthexplorer.usgs.gov/. Satellite images were selected based on district where sequence patterns took place and date when sequence patterns occurred.

Two images were found suitable for the sequences namely for the area Pontianak on 8 September 2015, and Pulang Pisau and Palangkaraya on 14 October 2015. Both the images were preprocessed, classified and filtered to get burned area. Filling the gap, band combinations and subsets of images were done in the preprocessing stage.

The entire Landsat 7 satellite imagery began on 3 May 2003 has a gap due to damage on the SLC. The gap causes pixels to have no value.
Such a gap will also lead to low quality of classification results. For these reasons, it was necessary to fill the gap by estimating the value of the missing pixels. This study conducted gap filling using the QGIS software and gap mask obtained from the USGS. Filling gap was done on each band using the gap mask for band that operated. Fig. 2 shows the result of filling gap on bands 7, 4 and 2 .

\section{Sequential Patterns using Prefix Span Algorithm}

In this study, sequential pattern mining was performed on the sequence dataset of hotspot in Kalimantan in 2014 and 2015. The value of minimum support used was $1 \%$. The resulting pattern has length of 1 event to 3 events. For further analysis, only sequence patterns of length 2 to 3 events were used because such patterns are considered to become fire spots.

Table 2 shows number of sequence patterns of hotspots for each dataset generated using PrefixSpan algorithm that is available in the sequential pattern mining framework (SPMF) (http://www.philippe-fournier-

viger.com/spmf/).

Table 1 Sample of hotspot sequences in Kalimantan 2015

\begin{tabular}{ccc}
\hline Longitude & Latitude & Sequence \\
\hline 108.94 & 0.80 & $728-2$ \\
109.48 & -0.53 & $629-1622-2$ \\
109.12 & $0: 32$ & $622-1627618-1628-1630-1-2$ \\
\hline
\end{tabular}

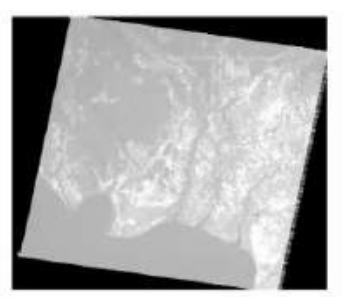

Band 7

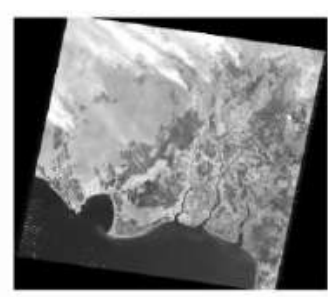

Band 4

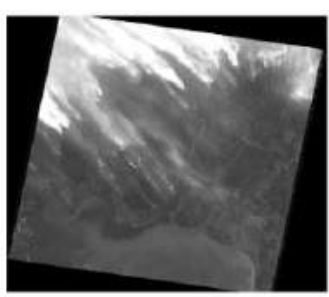

Band 2

Figure 2 Example of filling gap on bands 7, 4 and 2

Table 2 Number of sequence pattern of hotspots

\begin{tabular}{cccccccccccccc}
\hline & \multicolumn{1}{c}{ West Kalimantan } & \multicolumn{2}{c}{ South Kalimantan } & \multicolumn{3}{c}{ Central Kalimantan } & \multicolumn{2}{c}{ East Kalimantan } & \multicolumn{2}{c}{ Kalimantan Island } \\
\hline Event & $\mathbf{1}$ & $\mathbf{2}$ & $\mathbf{1}$ & $\mathbf{2}$ & $\mathbf{1}$ & $\mathbf{2}$ & $\mathbf{3}$ & $\mathbf{1}$ & $\mathbf{2}$ & $\mathbf{3}$ & $\mathbf{1}$ & $\mathbf{2}$ \\
\hline 2014 & 49 & 6 & 28 & 6 & 30 & 3 & 0 & 40 & 21 & 2 & 32 & 2 \\
2015 & 35 & 14 & 31 & 5 & 45 & 10 & 1 & 42 & 1 & 0 & 45 & 7 \\
\hline
\end{tabular}


Table 2 explains that the sequence patterns in 2014 widely occurred in East Kalimantan. As in 2015, the sequence patterns were common in West Kalimantan and Central Kalimantan. In West Kalimantan, there were 14 sequences with the length of 2 events while in Central Kalimantan, there were 10 sequences with the length of 2 events and 1 sequence with the length of 3 events.

In this study, the sequence patterns in West Kalimantan and Central Kalimantan in 2015 were analyzed further. Table 3 represents the results of sequence patterns in 2015 in West and Central Kalimantan with the length of 2 and 3 events. Those patterns were mostly found in Kubu Raya and Pontianak, West Kalimantan and also in Pulang Pisau and Palangkaraya, Central Kalimantan.

As many as 23 sequence patterns with lengths of 2 or 3 events generated in 2014 were mostly found in East Kalimantan, especially in Ketapang and Sambas on 26 September 2014. In addition, sequence pattern of hotspots was frequently found in West Kalimantan and Central Kalimantan in 2015. As many 14 sequences with length of 2 events were found in West Kalimantan especially in Ketapang and Kayong Utara on 10 and 21 September 2015. Furthermore, there were 11 sequences with length of 2 or 3 events found in Central Kalimantan, especially in Kapuas and Katingan on 9 and 14 October 2015.

\section{Satellite Image Classification using Maximum Likelihood}

This study used the band combination of 7, 4 and 2. This combination is valid to be used to detect the burned area (Quinn 2001). To get the image in peatlands, it is necessary to process the image subset. To obtain the image subset, image overlay and clipping using peatlands map was done. Overlay was conducted to determine the area of peatland, and clipping process was done to take part of peatland only. Fig. 3 illustrates the overlay and clipping process.

Table 3 Hotspot sequence patterns in West and Central Kalimantan 2015

\begin{tabular}{|c|c|c|c|c|}
\hline Province & $\begin{array}{l}\text { Sequence 2-events } \\
\text { (in date code) }\end{array}$ & Sequences date & $\begin{array}{l}\text { Sequence 3-events } \\
\text { (in date code) }\end{array}$ & $\begin{array}{c}\text { Sequences } \\
\text { date }\end{array}$ \\
\hline West & 549 -1 552 -1 \#SUP: 8 & $03 / 07 / 2015-06 / 07 / 2015$ & - & - \\
\hline \multirow[t]{13}{*}{ Kalimantan } & $549-1550-1$ \#SUP: 8 & $03 / 07 / 2015-04 / 07 / 2015$ & & \\
\hline & $608-1609-1$ \#SUP: 8 & $31 / 08 / 2015-01 / 09 / 2015$ & & \\
\hline & 609 -1 616 -1 \#SUP: 13 & $01 / 09 / 2015-08 / 09 / 2015$ & & \\
\hline & $609-1611-1$ \#SUP: 11 & $01 / 09 / 2015-03 / 09 / 2015$ & & \\
\hline & 613 -1 616 -1 \#SUP: 10 & $05 / 09 / 2015-08 / 09 / 2015$ & & \\
\hline & 616-1 618-1 \#SUP: 14 & $08 / 09 / 2015-10 / 09 / 2015$ & & \\
\hline & 617 -1 618 -1 \#SUP: 11 & $09 / 09 / 2015-10 / 09 / 2015$ & & \\
\hline & $618-1659-1$ \#SUP: 8 & $10 / 09 / 2015-21 / 10 / 2015$ & & \\
\hline & $618-1622-1$ \#SUP: 9 & $10 / 09 / 2015-14 / 09 / 2015$ & & \\
\hline & $622-1629-1$ \#SUP: 9 & $14 / 09 / 2015-21 / 09 / 2015$ & & \\
\hline & $629-1630-1$ \#SUP: 20 & $21 / 09 / 2015-22 / 09 / 2015$ & & \\
\hline & $629-1659-1$ \#SUP: 10 & $21 / 09 / 2015-21 / 10 / 2015$ & & \\
\hline & $634-1659$-1 \#SUP: 16 & $26 / 09 / 2015-21 / 10 / 2015$ & & \\
\hline Central & $615-1616-1$ \#SUP: 52 & $07 / 09 / 2015-08 / 09 / 2015$ & $647-1652-1$ & $09 / 10 / 2015$ \\
\hline \multirow[t]{9}{*}{ Kalimantan } & $622-1629-1$ \#SUP: 49 & $14 / 09 / 2015-21 / 09 / 2015$ & $654-1$ & - \\
\hline & $629-1631$-1 \#SUP: 134 & $21 / 09 / 2015-23 / 09 / 2015$ & \#SUP: 47 & $14 / 10 / 2015$ \\
\hline & $640-1652-1$ \#SUP: 48 & $02 / 10 / 2015-14 / 10 / 2015$ & & - \\
\hline & $645-1647-1$ \#SUP: 61 & $07 / 10 / 2015-09 / 10 / 2015$ & & $16 / 10 / 2015$ \\
\hline & 647 -1 652 -1 \#SUP: 106 & $09 / 10 / 2015-14 / 10 / 2015$ & & \\
\hline & $647-1654-1$ \#SUP: 66 & $09 / 10 / 2015-14 / 10 / 2015$ & & \\
\hline & $652-1654$-1 \#SUP: 150 & $14 / 10 / 2015-16 / 10 / 2015$ & & \\
\hline & $652-1657-1$ \#SUP: 72 & $14 / 10 / 2015-19 / 10 / 2015$ & & \\
\hline & $659-1661-1$ \#SUP: 63 & $21 / 10 / 2015-23 / 10 / 2015$ & & \\
\hline
\end{tabular}


To perform image classification, sampling was necessary. In this study, red pixels were taken as samples of burned class, while other colors were taken as the samples of not burned class. Then the samples were used to perform the image classification using ILWIS software

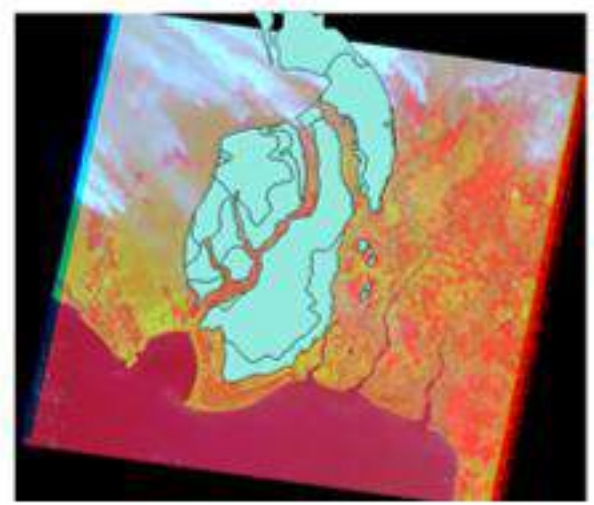

(a) Overlaying the image (https://www.itc.nl/ilwis/). Fig. 4 shows the result of image classification for Pulang Pisau compared to its original image. Fig. 5 shows the result of image classification for Palangkaraya compared to its original image.

Figure 3 Overlaying (a) and clipping (b) the image with peatland map

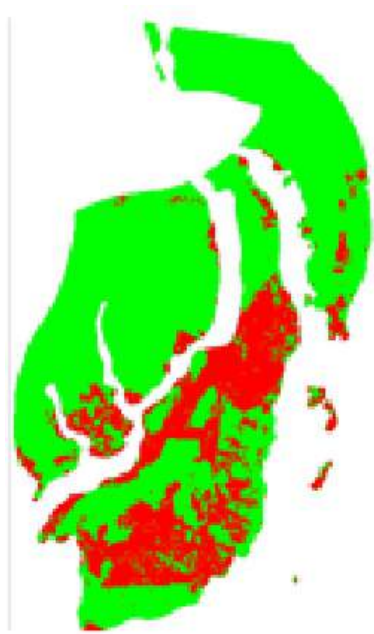

(a)

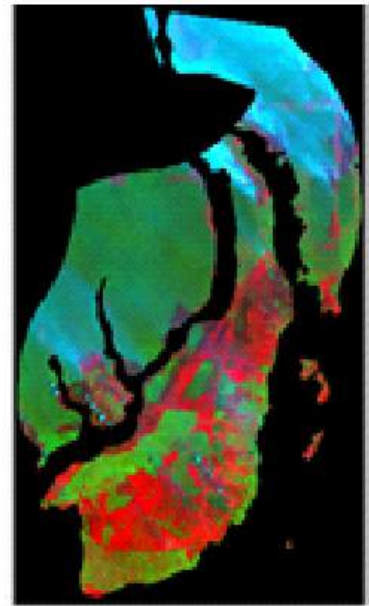

(b)

Figure 4 Pulang Pisau image: classification results (a) and original image (b)

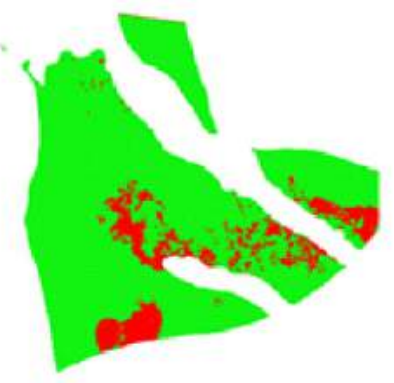

(a)

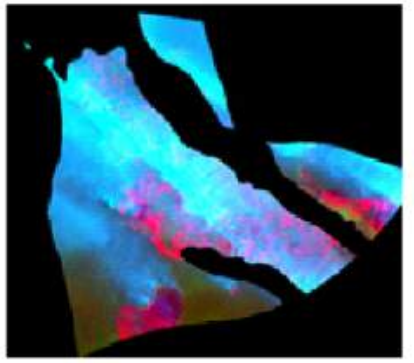

(b)

Figure 5 Palangkaraya image: classification results (a) and original image (b) 
In Fig. 4 and 5, the red color represents burned areas, while green represents unburned areas. These figures show the classification results close to the original images and thus considered good enough. Image classification results were used in the fire spot identification.

\section{Fire Spot Identification}

To get accurate locations of hotspot sequences, values of longitude and latitude of sequence patterns were restored to 3 decimal places. Furthermore, patterns that occur in the same period of the imagery were selected. The classified image was overlaid with selected sequence pattern. Fig. 6 shows sequence patterns overlaid with classified image for area of Pulang Pisau and Palangkaraya.

Sequence patterns in burned area and not burned area were determined by executing the SQL statements. If a pattern is in the area on fire, then it is labeled as "yes", otherwise it is labeled as "no". A MODIS hotspot is one of indicators for forest and land fire that occur in the radius of $1 \mathrm{~km}$. Therefore, this study calculates not only sequence patterns of hotspots in burned area but also in surrounding burned area. To perform this step, identification was also done in buffer with the radius of $1 \mathrm{~km}$ around burned area.

The sequence patterns of hotspot located in the burned area represents fire spots. The sequence patterns of hotspot located in the buffer of burned areas represent sequence patterns around area of peatland fires. Table 4 shows percentage of sequence patterns of hotspots in burned area and in the buffer area.

From Table 4, it is known that percentage of sequence patterns in burned and buffer area is greater than those only in burned area. It is caused by inability of the classification algorithm to identify burned area in the image where there is much smoke. With this taken into account, it can be concluded that in Pulang Pisau there were $72.62 \%$ sequence patterns that become forest fire. Meanwhile in Palangkaraya, there were $87.50 \%$ sequence patterns that become forest fire.

Table 4 Percentages of sequence patterns of hotspots in burned and buffer areas

\begin{tabular}{ccc}
\hline Area & In burned area & In burned and buffer area \\
\hline Pulang Pisau & $26.19 \%$ & $72.62 \%$ \\
Palangkaraya & $62.50 \%$ & $87.50 \%$ \\
\hline
\end{tabular}

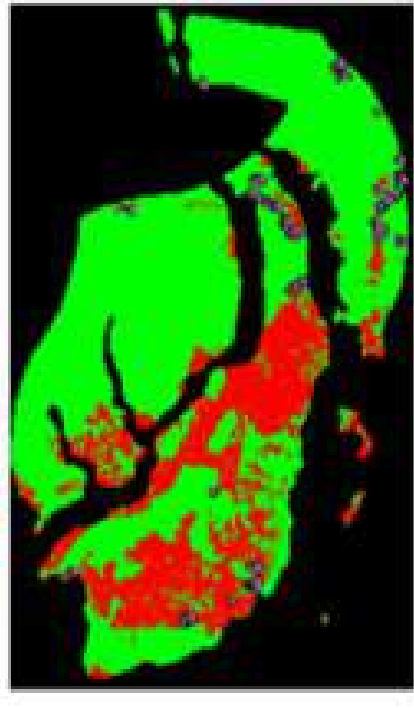

(a) Pulang Pisau

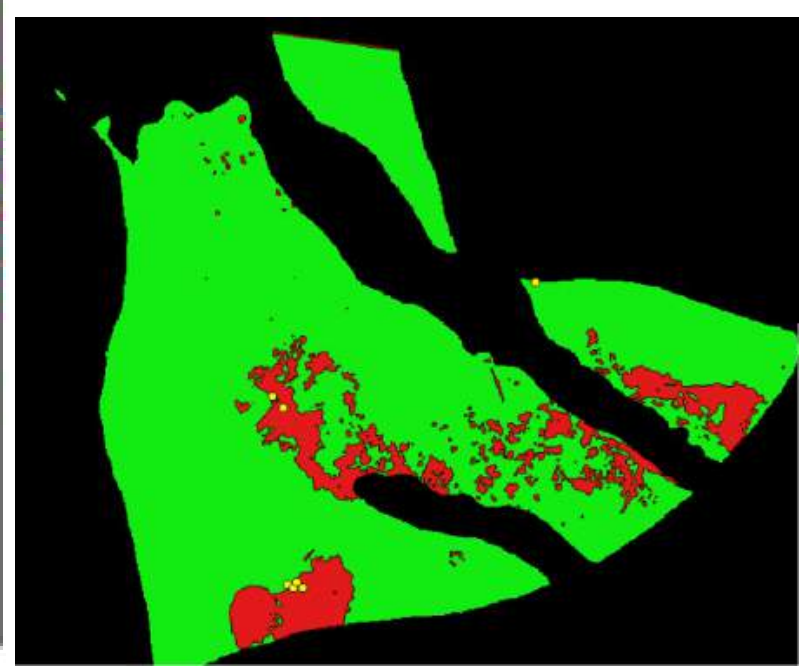

(b) Palangkaraya

Figure 6 Sequence patterns of hotspots overlaid with classified images for (a) Pulang Pisau and (b) Palangkaraya 


\section{CONCLUSION}

The Prefix Span algorithm was successfully applied to determine the sequence patterns of hotspots in two peatland areas in Kalimantan for 2014 and 2015. Sequence patterns with lengths of 2 or 3 events generated in 2014 were mostly found in Ketapang and Sambas, East Kalimantan. In addition, sequences with length of 2 events were found especially in Ketapang and Kayong Utara, West Kalimantan in 2015. In Central Kalimantan, hotspot sequences with length of 2 or 3 events were mostly found in Kapuas and Katingan in 2015.

The experimental result showed that for Pulang Pisau, there are $26.19 \%$ and $72.62 \%$ sequence patterns that are located in burned areas and in the buffer area, respectively. As for Palangkaraya, there are $62.50 \%$ and $87.50 \%$ sequence patterns that are located in burned areas and in the buffer area, respectively. This study shows that about $72.62 \%$ and $87.50 \%$ hotspots sequentially occurred in Pulang Pisau and Palangkaraya, respectively. Those hotspots are considered as fire spots that become strong indicator for peatland fires.

\section{ACKNOWLEDGEMENTS}

The authors would like to thank Directorate of Research and Community Service, Ministry of Research, Technology and Higher Education, Republic of Indonesia, for the research grant.

\section{REFERENCES}

Canty MJ. 2010. Image analysis, classification, and change detection in remote sensing, $2^{\text {nd }}$ edition. Boca Raton, FL (US): CRC Press.

Justice CO, Malingreau JP, Setzer AW. 1993. Satellite remote sensing of fires: Potential and limitations. In: Crutzen PJ, Goldammer JG, editors. Fire in the Environment: The Ecological, Atmospheric, and Climatic Importance of Vegetation Fires. Hoboken, NJ (US): John Wiley \& Sons Ltd. p. 7788.
Kirana AP, Sitanggang IS, Syaufina L. 2015. Poisson clustering process on hotspot in peatland area using Kulldorff's scan statistics method. TELKOMNIKA 13(4):1376-83.

Khaira U, Sitanggang IS, Lailan S. 2016. Detection and prediction of peatland cover changes using support vector machine and markov chain model. TELKOMNIKA 14(1):294-301.

Lu D. 2007. A survey of image classification methods and techniques for improving classification performance. Int J Remote Sens 28(5):823-70.

Mitri G, Gitas I. 2002. The development of an objectoriented classification model for operational burned area mapping on the Mediterranean island of Thasos using Landsat-TM images. In: Viegas DX, editor. Forest Fire Research and Wildland Fire Safety. Rotterdam (NL): Millpress. p. 79.

Nurulhaq NZ, Sitanggang IS. 2015. Sequential pattern mining on hotspot data in Riau province using the PrefixSpan algorithm. In: ICAIA 2015. Proceedings: 2015 Aug 5-3; Bogor. Jakarta (ID): IEEE Indonesia. p. 257-60.

Pei J, Han J, Mortazavi-Asl B, Wang J, Pinto H, Chen Q, ... Hsu M. 2004. Mining sequential patterns by pattern-growth: The Prefix Span approach. IEEE Trans Knowl Data Eng 16(11):1424-40.

Sitanggang IS. 2013. Spatial multidimensional association rules mining in forest fire data. JDAIP 1(4):90-6.

Sitanggang IS, Yaakob R, Mustapha N, Ainuddin AN. 2014. A decision tree based on spatial relationships for predicting hotspots in peatlands. TELKOMNIKA 12(2):511-8.

Sitanggang IS, Yaakob R, Mustapha N, Ainuddin AN. 2015. Burn area processing to generate false alarm data for hotspot prediction models. TELKOMNIKA 13(3):1037-46.

Syaufina L. 2008. Kebakaran hutan dan lahan di Indonesia: Perilaku api, penyebab, dan dampak kebakaran [Forest and land fires in Indonesia: Fire behavior, causes and impacts of fires]. Malang (ID): Bayumedia Publishing.

Thariqa P, Sitanggang IS, Syaufina L. 2016. Comparative analysis of spatial decision tree algorithms for burned area of peatland in Rokan Hilir Riau. TELKOMNIKA 14(2):684-91.

Quinn JW [internet]. 2001. Band combinations. Portland, OR (US): Portland State University; [updated 2015 May 28]. Available from: http://web.pdx.edu/ emch/ip1/bandcombinatio ns.html 